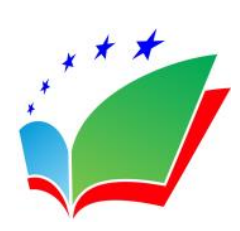

European Journal of Physiotherapy and Rehabilitation Studies

ISSN: 2668-9928

ISSN-L:2668-9928

Available on-line at: $\underline{\text { www.oapub.org/hlt }}$

DOI: 10.46827/ejprs.v2i1.53

Volume 2 | Issue 1 | 2021

\title{
EFFECTIVENESS OF HIGH AND LOW INTENSITY \\ REHABILITATION PROGRAMME IN CHRONIC PHASE \\ OF GUILLAIN BARRE SYNDROME PATIENTS: A RANDOMIZED CONTROL TRIAL
}

\author{
Gourav Kumar', \\ Lalit Arora ${ }^{2 i}$, \\ Reena Arora ${ }^{2}$ \\ ${ }^{1}$ MPT Student, \\ University College of Physiotherapy, \\ Baba Farid University of Health Sciences, \\ Faridkot, Punjab, India \\ ${ }^{2}$ Lecturer, \\ University College of Physiotherapy, \\ Baba Farid University of Health Sciences, \\ Faridkot, Punjab, India
}

\begin{abstract}
:
Aim of the study: The aim of the study was to conduct a randomized control trial to compare the effectiveness of high and low intensity rehabilitation programme in chronic phase of GBS patient. Methodology: 20 Patients were included in the study as per inclusion and exclusion criteria. A written informed consent was signed by the subjects in their native language. The subjects were divided into two groups by simple random sampling. Group (A) Experimental Group ( $\mathrm{N}=10)$ : got treatment with High intensity rehabilitation exercises and Group (B) Control Group ( $\mathrm{N}=10)$ : got treatment with Low intensity rehabilitation exercises. Total rehabilitation program was for 12 months. The outcome measures for the both groups were Functional Independence Measure (FIM), World health Organization Quality of Life Scale (WHOQOL-BREF), Perceived Impact of Problem Profile (PIPP). Results: Intention to treat analysis of data from 20 patients (experimental $n=10$, control $n=10$ ) showed reduced disability in the treatment group in post-treatment FIM domains (self- care, sphincter control, transfers, locomotion; all $\mathrm{p}<0.001$ ) and WHOQOL-BREF domains (quality of life; all $\mathrm{p}<0.001$ ) and PIPP domains (self-care, mobility; all $\mathrm{p}<0.001$ ). The treatment group compared with control group showed significant improvement in function (FIM scores): $72 \%$ vs. 50\%. Conclusion: High intensity rehabilitation programme compared with Low intensity low intensity
\end{abstract}

iCorrespondence: email lalitarora1635@gmail.com 
rehabilitation programme is effective in reducing motor disability (mobility, self-care, continence) in chronic phase of GBS patients.

Keywords: chronic phase of GBS, high intensity exercises, low intensity exercises

\section{Introduction}

Guillain-Barre syndrome (GBS), an immune-based illness, presents as evolving acute polyneuritis, usually with motor deficits (symmetrical ascending paralysis), autonomic dysfunction and respiratory failure. ${ }^{1}$ GBS is an immune mediated polyneuropathy characterized by progressive weakness in all four limbs, areflexias, autonomic dysfunction and respiratory paralysis. The onset and presentation of symptoms may vary. It is considered to be the most important cause of muscle paralysis in developing countries after poliomyelitis. ${ }^{2}$

The disease incidence in India is similar to that of other developed countries: 1-2 patients per 100,000 population with male to female ratio of $2: 1$. This disease has generally favourable outcome (majority of the patient starts ambulation with-in 6 months of the onset of the symptoms) with low mortality rate. However, $25 \%$ of the patients may require ventilator assistance, and $10-20 \%$ of the patient may have severe residual permanent disability. Commonly recognized variant of GBS include acute inflammatory demyelinising polyneuropathy (AIDP), acute sensory and motor axonal polyneuropathy, Miller Fisher syndrome (MFS), and Acute motor axonal neuropathy (AMAN). Chronic phase of GBS means residual weakness present after six month of first symptom of GBS3.

A lot of studies have been done on the initial management of the disease but there is a paucity of studies on long term relationship including physiotherapy management of the chronic phase of GBS patients. GBS is an immune mediated peripheral neuropathy primarily characterized by rapidly evolving symmetrical limb weakness. The weakness can be variable, from minimal lower extremity weakness to total paralysis of all extremities and trunk. Symptoms become more severe until they reach maximum expression; a plateau phase of 2-4 weeks follows, and recovers completely within 1 month after the onset. But in rare cases there is a gradual resolution of the paralysis that can last 1-2 years and the patient recovers within a period of 6 months to two years ${ }^{4}$.

\section{Procedure}

Total 20 patients were included in the study based on inclusion and exclusion criteria. Patients were selected from GGS Medical College and Hospital, Faridkot; OPD, University College of Physiotherapy, Faridkot; Civil hospital, Faridkot and Civil hospital, Kotkapura with confirmed diagnosis of chronic GBS. Inclusion criteria was Both male and female with age between 30-60 years, Patients with stable motor neuropathy with or without sensory neuropathy, Able to walk $10 \mathrm{~m}$, without walking aid, At least one year since onset if they have Guillain-Barre syndrome, Having no change in self-reporting 
disability, Immunotherapy or medication for neuropathic the previous six month, Participants should not have received physiotherapy treatment in the 24 month prior to entering the study, able to understand spoken or written Punjabi and were able to communicate responses to questionnaires. Exclusion criteria was patient having another unstable medical condition that affect activity limitation or prevents them from exercising or would make it unsafe to exercise, Patients with altered sensorium, Not able to understand command. They were divided into two equal groups by randomly allocating using Lottery method - Group A and Group B i.e. ten patients in each group. A written informed consent was signed by the subjects in their native language.

Patients were assessed at 0 day before giving treatment and re-assessed at the end of $6^{\text {th }}$ month and at the end of $12^{\text {th }}$ month. Patients completed demographic, functional assessments and health related QoL measures using standardized instruments i.e. FIM, PIPP \& WHOQoL-BREF. Treatment was given for a total period of 12 months. Treatment sessions were given two times per week for 40 minutes per session.

Group A (Experimental group):10 patients in group A were treated with high intensity rehabilitation programme (HIRP) in which major concentration was given on strengthening, endurance and gait training. HIRP included treatment beyond symptomatic management of GBS and education to improve activity and participation within the limits of disease. The elements included individualized, achievable, time based, functional goal oriented multidisciplinary treatment with active patient participation ${ }^{1}$.

Treatment in this group was given two times per week for one year. Forty minutes of session included five minutes of warm up period followed by thirty minutes of high intensity programme which was followed by five minutes of cool down period. The warm up session included bilateral shoulder flexion, extension, abduction and external rotation followed by bilateral hip joint movements which included bilateral hip flexion, extension and rotation. All movements which are mentioned above were for 10 counts. In high intensity programme, it started with ten minutes of cycling ${ }^{5}$ on Static cycle followed by ten minutes of Ramp-Staircase ${ }^{6}$ walking and in last ten minutes Parallel bar walking. Cool down period included breathing exercises.

Group B (Home Based- Low Intensity Rehabilitation Programme <LIRP>):10 patients in group $B$ were treated with LIRP. Treatment in this group was given two times per week for one year. Treatment session lasted for 40 minutes. Forty minutes of session included twenty minutes of walking at slow speed ${ }^{7}$ followed by twenty minutes of lower limb muscles self-stretching. Stretching was done on following major muscle groups' quadriceps, hamstrings and gastro soleus.

\section{Data Analysis and Results}

Data was analysis by using SPSS Version 19. Unpaired t- test and Repeated Anova test were used to determine the effectiveness of high and low intensity rehabilitation programme: a randomized control trial. 


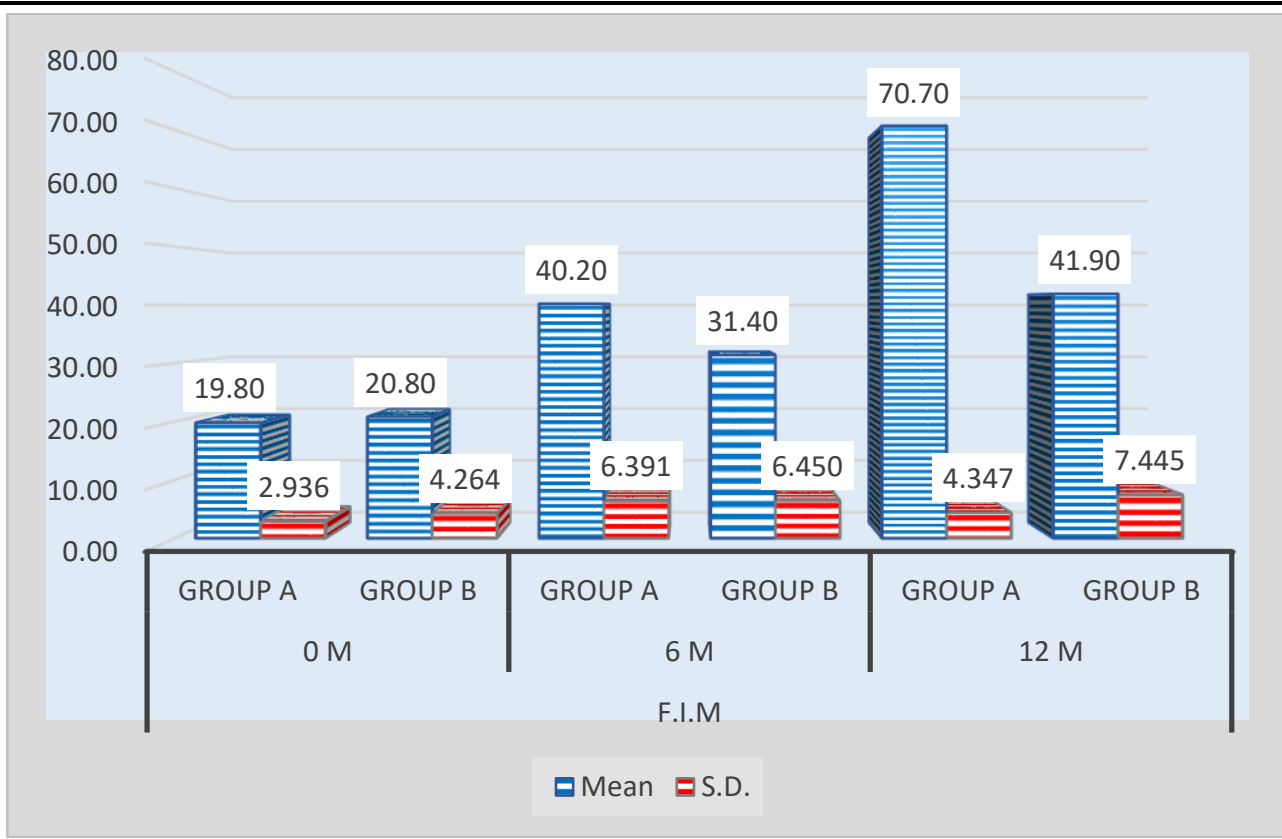

Figure 1.1: Intergroup comparison of Group A and Group B at $\mathrm{o}$ day, $6^{\text {th }}$ month, $12^{\text {th }}$, month (FIM Scale)

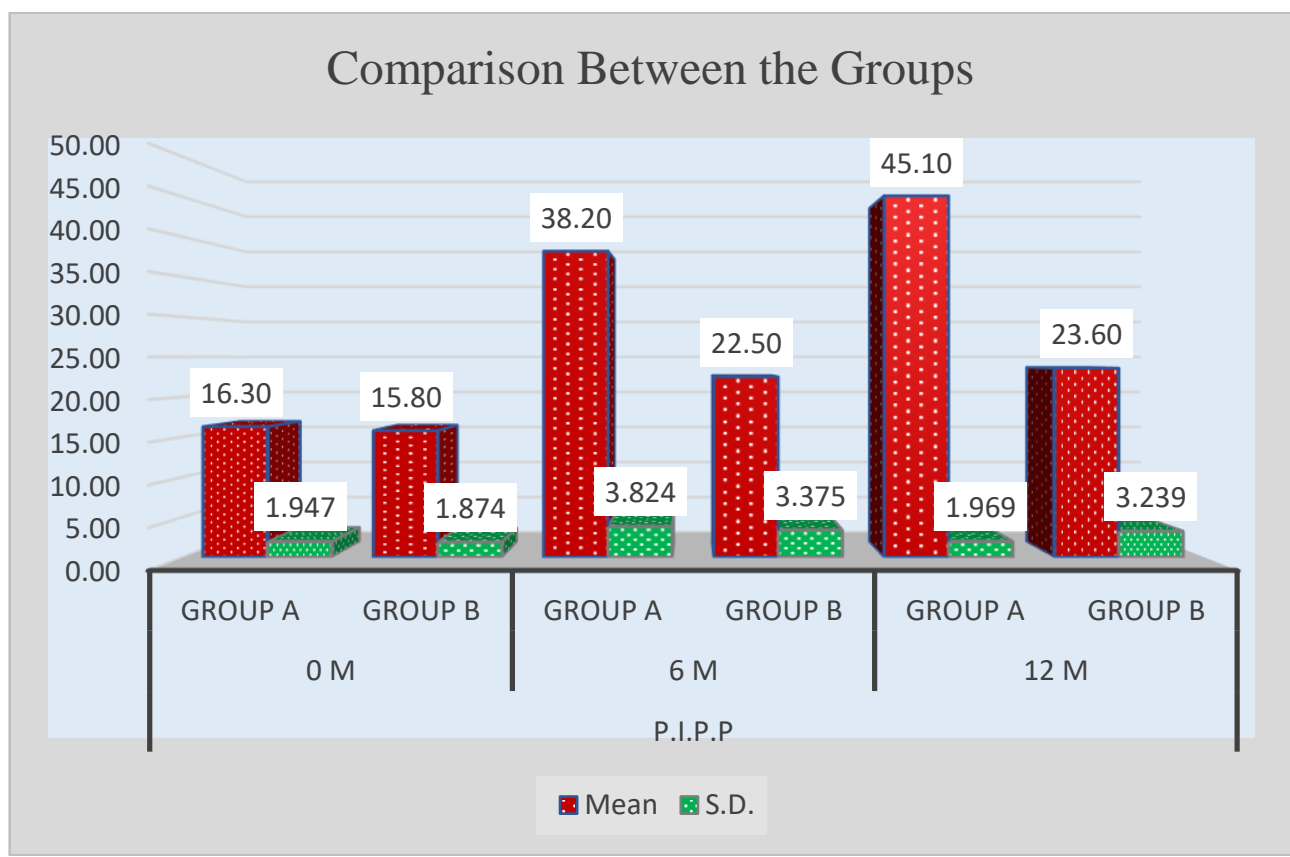

Figure 1.2: Intergroup comparison of Group A and Group B at o day, $6^{\text {th }}$ month, $12^{\text {th }}$, month (PIPP Scale) 


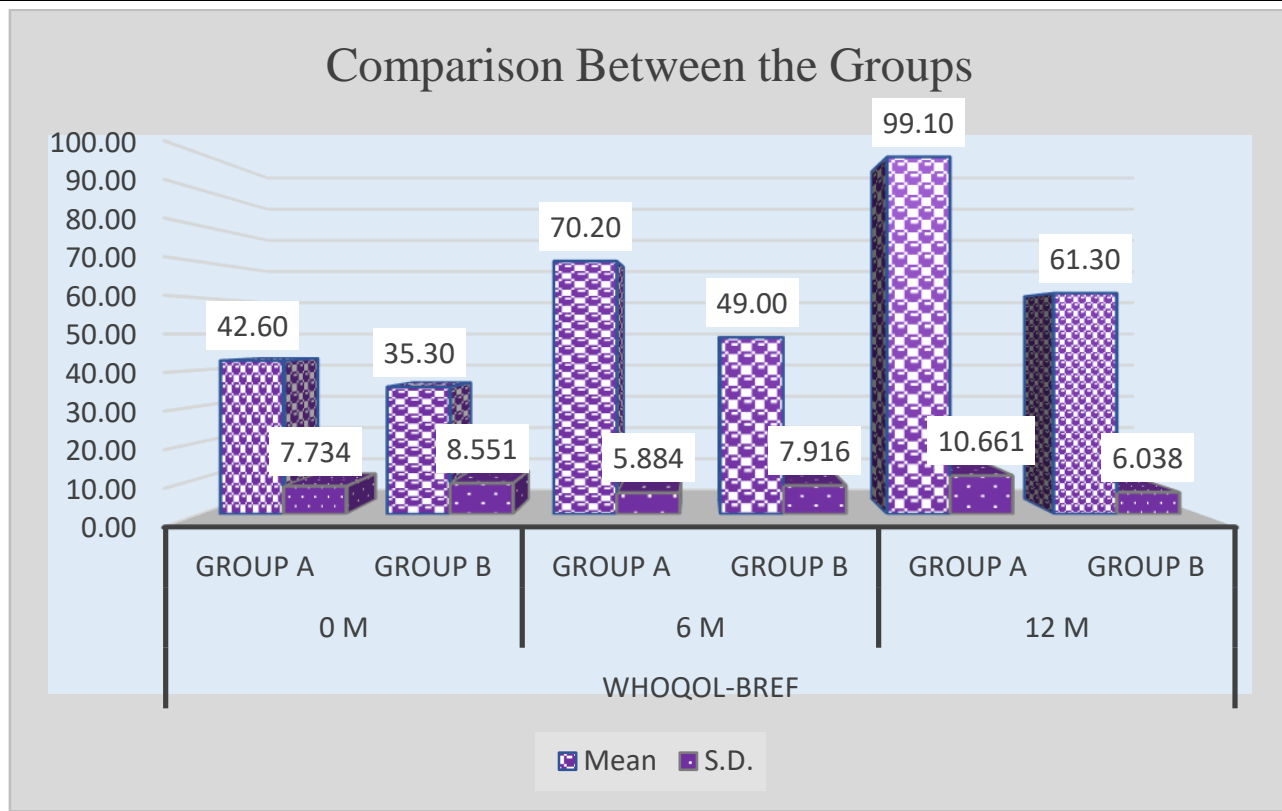

Figure 1.3: Intergroup comparison of Group A and Group B at o day, $6^{\text {th }}$ month, $12^{\text {th }}$, month (WHOQOL-BREF Scale)

\section{Discussion}

The present study identified problems relating to mobility, major life areas and interpersonal relationship as prioritized by chronic GBS patients. Persons with GBS report significant longer term psychological sequelae with moderate to extreme impact on their ability to participate in work, family and social activities greater depression and anxiety compared to normal. This study concluded that both high and low intensity exercises are effective in reducing motor disability (mobility, self-care, continence) in chronic phase of GBS patients. However, it is concluded that high intensity exercises (cycling, ramp-staircase, parallel bar) are better than low intensity exercises (walking, stretching) to reduce motor disability and have positive impact in chronic phase of GBS patients compared with a lesser intensity programme at 12 months. It is statistically proved that the patients will recover at 12 months with a statistically significance of FIM scale $\mathrm{p}<00.001$, PIPP scale $\mathrm{p}<0.001$, WHOQOL- BREF scale $\mathrm{p}<0.001$. A high intensity rehabilitation programme in chronic phase of GBS patients leads to faster motor function achievement in relation to low intensity rehabilitation programme. The result of the present study is in accordance with study by Sarah Rodgers et al. (2017) who conducted a gait and balance training programme on a GBS patients. After 12 weeks of training, the patients significantly improved with his functional mobility. Khan F. et al. (2011) conducted a study on Outcomes of high- and low intensity rehabilitation programme for persons in chronic phase in GBS and concluded that higher intensity rehabilitation compared with less intense intervention reduces disability in patient with GBS in later stages of recovery. ${ }^{1}$ 


\section{Conclusion}

This study concluded that high and low intensity rehabilitation programme is effective in enhancing motor function \& reduce disability. However, it is concluded that high intensity rehabilitation programme compared with low intensity rehabilitation programme reduces disability and enhancing motor function in chronic phase of GBS patients. Motor functions improved highly significantly after 12-month treatment with high intensity rehabilitation programme as compared with low intensity rehabilitation programme. Future studies can be done on acute case of GBS patients using different outcome measures.

\section{Conflict of Interest Statement}

The authors declare no conflicts of interests.

\section{About the Authors}

Gourav Kumar is a Post graduate student pursuing Master in Physiotherapy (Neurology).

Lalit Arora is Master of Physiotherapy (Neurology) and pursuing PhD in Physiotherapy. He has sixteen years of clinical as well as academic experience. He has keen interest in research related especially to neurological rehabilitation.

Reena Arora is Master of Physiotherapy (Orthopedics). She has sixteen years of clinical as well as academic experience. Both the above authors are working as assistant professor in Health Science University.

\section{References}

1) Khan, F., Ng, L., Amatya, B, et al. (2011). Multidisciplinary care for Guillain-Barré syndrome. European journal of physical and rehabilitation medicine; 47(4), 607612.

2) Manisha Shrivastava, Nehal Shah, et al. (2018). Comparison of the outcomes of home based and supervised individually designed exercise programme amongst the patients in chronic phase after Guillain barre syndrome: study protocol for a randomized control trial. International journal of clinical trial; 5(1): 60-66

3) Shah Nehal, Shrivastava et al. (2015). Role of physiotherapy in Guillain Barre Syndrome: A Narrative Review. International journal of health sciences and research; 5(9) 529-540.

4) Snehal Waghavkar, Suvarna Ganvir et al. (2016). Enhancement of recovery with physical therapy management in patient of rare variety of Guillain Barre Syndrome: A Case Report. Journal of physiotherapy and rehabilitation; 27(3)1-4.

5) Pitetti K. H., Barrett P. J., et al. (1993). Endurance exercise training in Guillain Barre syndrome. Arch Physical Medical Rehabilitation; 74(7):761-765. 
6) Nicholas Simatos et al. (2016). Conducted a study on Influence of Exercise on Patients with Guillain - Barre Syndrome Rehabilitation Sciences in Physical Therapy Program: A Review .Physiotherapy Canada; 68(4):367-376.

7) Ketaki Patani et al. (2014). Physiotherapy interventions : recurrent case of GuillainBarre syndrome of female adults patient: International journal of healthcare and research. journal of research; 3(1): 55-60. 5.

8) Andrew Dodds, et al. (1993). A Validation of the Functional Independence Measurement and its Performance Among Rehabilitation In patient. Arch Phys Medical Rehabilitation; 25(8): 531-65.

9) Pallant J. F., Bennett E., et al. (2006). Measuring the impact and distress of health problems from the individual's perspective: development of the perceived impact of problem profile (PIPP). Health Quality Life Outcomes; 4(12): 36-42.

10) T. (May 1998): Development of the World Health Organization WHOQOL-BREF Quality of Life Assessment. Psychological Medicine; 28(3): 551-558 doi:10.1017/S0033291798006667 

will be applied to their work. Under the terms of this license, no permission is required from the author(s) or publisher for members of the community to copy, distribute, transmit or adapt the article content, providing a proper, prominent and unambiguous attribution to the authors in a manner that makes clear that the materials are being reused under permission of a Creative Commons License. Views, opinions and conclusions expressed in this research article are views, opinions and conclusions of the author(s). Open Access Publishing Group and European Journal of Social Sciences Studies shall not be responsible or answerable for any loss, damage or liability caused in relation to/arising out of conflicts of interest, copyright violations and inappropriate or inaccurate use of any kind content related or integrated into the research work. All the published works are meeting the Open Access Publishing requirements and can be freely accessed, shared, modified, distributed and used in educational, commercial and non-commercial purposes under a Creative Commons Attribution 4.0 International License (CC BY 4.0). 